\title{
A Study on Stress Management by Middle Level Employees with Special Reference to Knowledge Process Outsourcing Company
}

\author{
R. Duraipandian1, Shishira Srinivasa ${ }^{2}$ \\ ${ }^{1}$ Head of Department- MBA, ${ }^{2}$ Senior Tax Associate \\ ${ }_{1}$ PES University, Bengaluru, Karnataka, India \\ 2KPMG Global services Limited, Bengaluru, Karnataka, India
}

\begin{abstract}
How to cite this paper: R. Duraipandian | Shishira Srinivasa "A Study on Stress Management by Middle Level Employees with Special Reference to Knowledge Process Outsourcing Company" Published in International Journal of Trend in Scientific Research and Development (ijtsrd), ISSN: 24566470, Volume-3 | Issue-3 , April 2019, pp.1142-1149, URL: https://www.ijtsrd.c om/papers/ijtsrd21 632.pdf

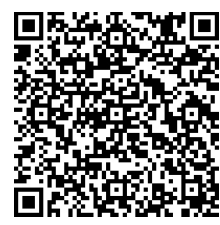

IITSRD21632
\end{abstract}

Copyright (c) 2019 by author(s) and International Journal of Trend in Scientific Research and Development Journal. This is an Open Access article distributed under the terms of the Creative Commons

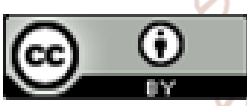
Attribution License (CC BY 4.0) (http://creativecommons.org/licenses/ by/4.0)

\section{INTRODUCTION}

\section{Literature Review:}

Weiss M. (1983) -The Author probed the sources of Job stress that is linked to Job dissatisfaction, Job related tension and anxiety which in lessened the productivity and effectiveness in the work performed by an employee. He tried to reduce sources of stress so that he can prevent the deleterious health consequences. Through his study he determined the prospects of social support that abate the detrimental consequences of stress.

Kodavatiganti K \& Bulusu V (2011)- The importance of the article was to have a precise understanding of the phenomenon that causes stress among the academicians. According to the article women educators faced comparatively higher level of stress than men counterparts. The stress amongst the academicians were mainly caused because of insufficient resources and long working hours, classrooms that are over filled than the capacity of it.

Khalid A. (2012)- The article implied that there was a direct relationship between stress and job performance in any organization. The article stated that in order to improve the performance of an individual in an organization an employee should receive good support from their leaders. It gave a conclusion that a supportive leader can improve the performance of an employee even at unfavourable situations and motivate him/her to perform at their level best.

Y. Tatheer (2013)- The article portrayed that majority of the bankers of Pakistan insisted that they are highly pressurized because of their jobs that not only affect their performance in banks but also affected their health and personal life, thereby harming their mental peace too. They also declared that the organizational politics and bureaucratical etiquette, unnecessary rules and regulations were all the main reasons of stress in their banks.

Rosasa J. H. A, Blevinsb R. C., Gaoc H., Tengb W. Y. \& White J. (2011)- The article reveals the levels of stress that differs by occupational designation, and not by age or gender or any other traits. The analysis showed that females had higher stress rates than males, who had higher designation at work and more pressure. 
Sapolsky, (2004) has explained how prediction of a stressful event can become a source of stress. Surprisingly, the body reacted in the same predictable way to an actual stressing event as it would to an anticipated stressing event (Sapolsky, 2004). Commonly accepted definitions of stress have also been provided by earlier researchers, such as (Selye, 1956; and Lazarus \& DeLongis, 1983).

Correlation between stressors such as role ambiguity, role conflict, role overload, resource inadequacy, underutilisation of skills and absenteeism have been found in other studies as well (Gupta \& Beehr, 1979; Jamal, 1984). In complete contrast to these observations there is another literature that shows that reducing role stressors (conflict and ambiguity) has the most remarkable impact on job satisfaction (Brown \& Peterson, 1993; Churchill, Ford, Steven, \& Walker, 1985; Jackson \& Schuler, 1985).

Van Rhenen et al., 2007 concluded that high levels of stress resulted in increased staff turnover, higher accident rates, more physical ill-health, more psychological ill-health and absenteeism. The article gave evidence to that fact that absenteeism in particular had become a major concern in industrialized 18 countries because of its economic consequences. For instance, sickness absence figures showed that the loss of working days for industry in the US amounted to about 550 million (3-7\%) each year and for the UK this figure is $3.7 \%$ of the total number of working days.

The remarkable phenomenon termed stress, experienced by human beings across their lifespan, is inexorable and is generally considered a physiological response to any stimulus (Cooper \& Dewe, 2008; Marcia, 2010). The study scrutinized two types of stress: positive and negative (Cooper \& Dewe, 2008; Woodward, Fletcher, \& 0' Donohue, 2006).

\section{Objectives of the research:}

The main objectives of the research are:

1. To get acquainted with different types of stress with examples

2. To discover the level of stress that the employees are facing in their work and identify the situations that are causing stress in the KPO industry.

3. To assess the feelings of employees about Stress

4. To recommend the measures to increase the proficiency of the employee at work and reducing their stress by considerate level

\section{Research methodology}

Two types of research would be used in the research:

1. Explorative

2. Descriptive

Exploratory research, as the name indicates merely to explore the research questions. The focus of the research is on gaining insights and familiarity for later analysis.

Descriptive research can be either quantitative or qualitative. The research involves collection of quantitative information that can be formulated along a continuum in numerical form. Data will be gathered that describes events and then will be organized, tabulated, depicted and visual aids such as charts and graphs will be used to represent them.

\section{Data sources:}

Primary data: primary data will be collected through survey from around 50 employees working in Knowledge process industry by administering a structured questionnaire at Bengaluru and also through observations, interview and discussion.

Secondary data: Along with primary data, data would be collected from journals, websites, research books and various management theories.

\section{Sampling:}

Using a convenient sampling, the questionnaires were distributed to 50 respondents through our own networks and we collected the responses.

\section{Phase One:}

\section{Different types of Stress:}

Acute stress: Acute stress is the most common form of stress. It comes from demands and pressures of the recent past and anticipated demands and pressures of the near future. Acute stress is thrilling and exciting in small doses, but too much is exhausting.

The most common symptoms are:

Emotional distress - some combination of anger or irritability, anxiety and depression, the three stress emotions.

Muscular problems including tension headache, back pain, jaw pain and the muscular tensions that lead to pulled muscles and tendon and ligament problems. Stomach, gut and bowel problems such as heartburn, acid stomach, flatulence, diarrhoea, constipation and irritable bowel syndrome.

Transient over arousal leads to elevation in blood pressure, rapid heartbeat, sweaty palms, heart palpitations, dizziness, migraine headaches, cold hands or feet, shortness of breath and chest pain.

Acute stress can crop up in anyone's life, and it is highly treatable and manageable.

\section{Episodic Acute Stress}

People who often experience acute stress, or whose lives present with frequent triggers of stress, have episodic acute stress. The individuals who frequently suffer acute stress often live a life of confusion, commotion, chaos and crisis. They are always in a rush or feel pressurized about every small thing. They take up numerous responsibilities, and normally cannot stay organized with so various time demands. These individuals are perpetually in the grips of acute stress overload.

\section{Chronic Stress}

Chronic stress is the most detrimental type of stress. If chronic stress is left untreated over a long period of time, it can significantly and often irreversibly damage one's physical health and deteriorate mental health.

For example, long term poverty, repeated abuse in any form, unemployment, dysfunctional family, poor work environment, substance abuse, or an unhappy marriage can cause significant chronic stress. 


\section{Phase Two:}

Feelings of Employees towards Stress:

$>$ A survey of 3,000 workers conducted by employee benefits platform Perk box found that work was the biggest cause of employee stress, followed by family pressures (45\%) and money worries (45\%).

$>$ Workers in the finance sector were affected the most, with $69 \%$ voiced that they felt stressed. This was closely followed by workers in local and national Government (68\%) and health (66\%).

$>$ Its 2018 UK Workplace Stress report determined that males aged 25 to 34 working in finance in Cardiff were the most likely to feel stressed at work. Geographical hotspots included Cardiff, with $70 \%$ of workers claiming they felt pressured, Wolverhampton (64\%) and London (59\%).

$>$ Overwork was given as the biggest reason for workplace strain $(21 \%)$. The most strained job function was sales: $79 \%$ of salespeople claimed that they felt stressed by their work. This was closely followed by HR personnel (76\%).

$>$ One in five $(21 \%)$ employees said their organisation offered flexible working arrangements to help combat stress and allow them to manage other personal commitments including childcare.

\section{Phase Three: \\ Conducting Research Survey:}

Data Collection: An online survey was created and circulated among employees of KPMG Bangalore, in US taxation department, from middle level employees of different age groups between 22 to 30 years old, who were at the designation level of Analysts and Senior Analysts in order to assess their level of stress and the symptoms that they experience and the feelings towards stress.

Here is the analysis of few questions that were a part of Questionnaire:

\section{Grouping/Filter Analysis:}

Graph 1: The below table depicts the difficulty faced by an employee at his/her job:

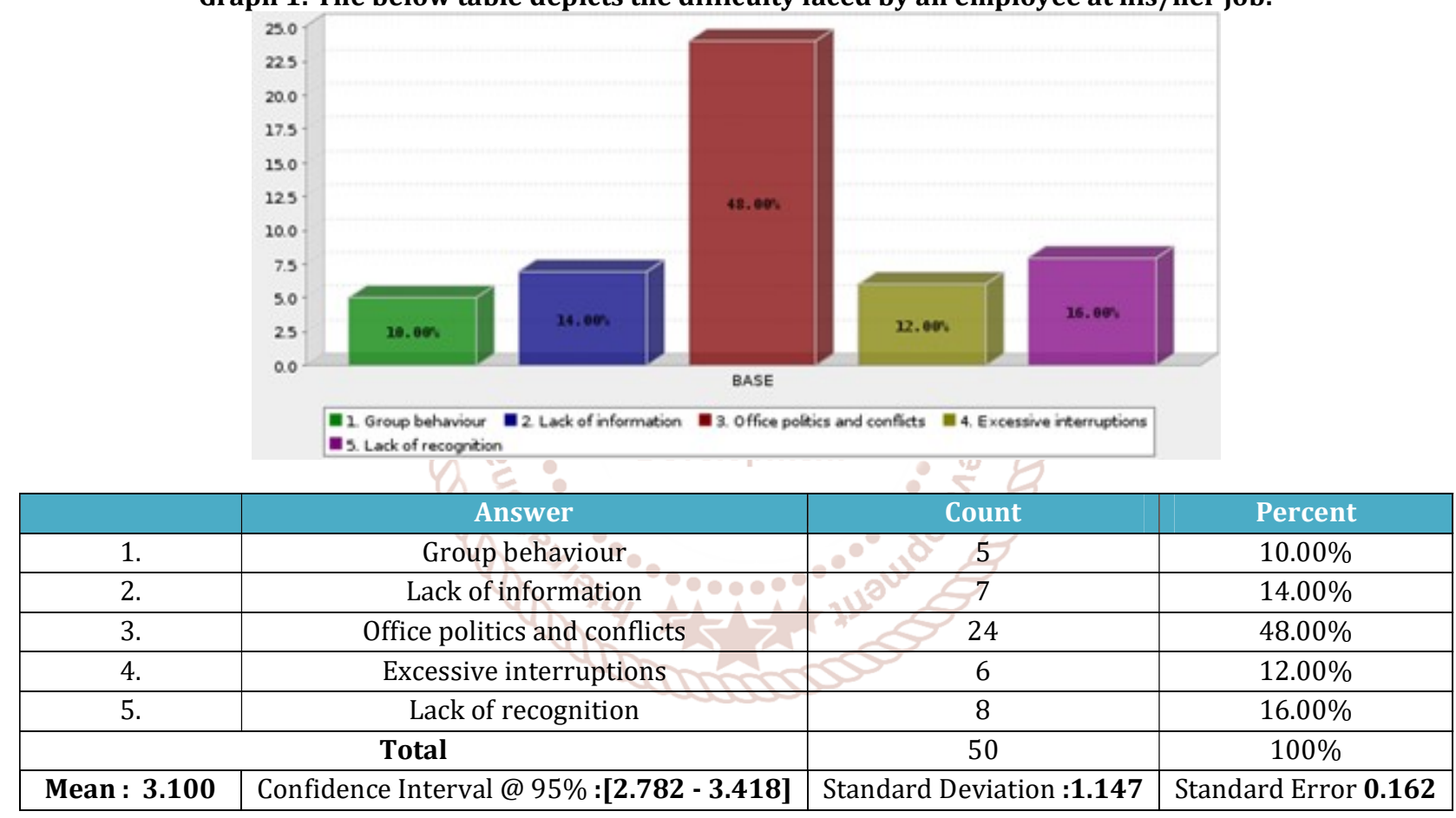

Interpretation: Out of the sample size of 50 employees, $48 \%$ were of the opinion that office politics and conflict were the major difficulty faced by them. This difficulty makes them more stressed at work.

Graph 2. The below bar chart depicts the percentage of physical and psychological problems faced by the employees due to stress

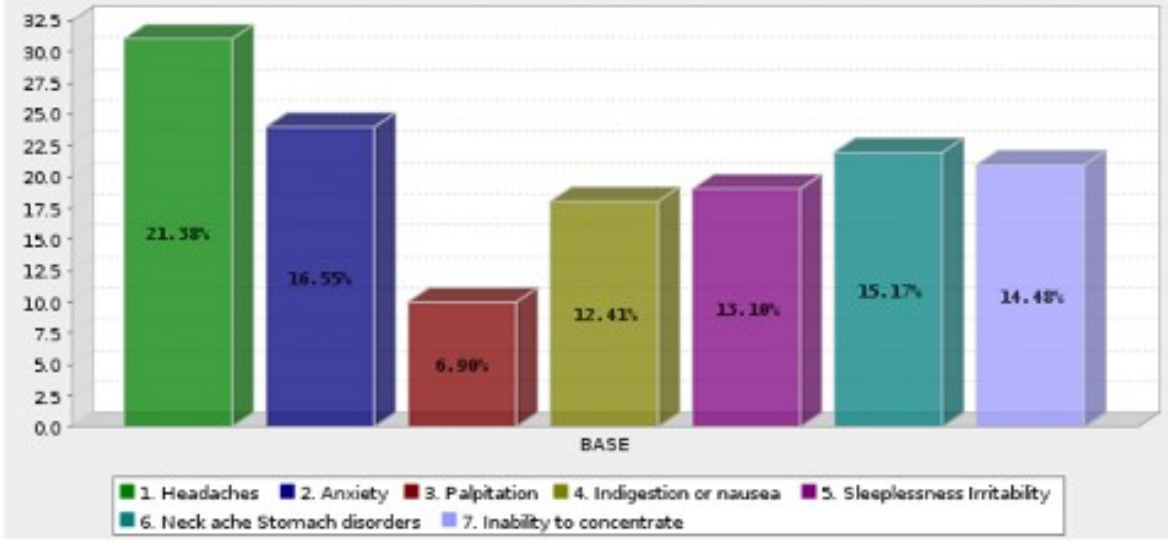


International Journal of Trend in Scientific Research and Development (IJTSRD) @ www.ijtsrd.com eISSN: 2456-6470

\begin{tabular}{|c|c|c|c|}
\hline & Answer & Count & Percent \\
\hline 1. & Headaches & 31 & $21.38 \%$ \\
\hline 2. & Anxiety & 24 & $16.55 \%$ \\
\hline 3. & Palpitation & 10 & $6.90 \%$ \\
\hline 4. & Indigestion or nausea & 18 & $12.41 \%$ \\
\hline 5. & Sleeplessness Irritability & 19 & $13.10 \%$ \\
\hline 6. & Neck ache Stomach disorders & 22 & $15.17 \%$ \\
\hline 7. & Inability to concentrate & 21 & $14.48 \%$ \\
\hline \multicolumn{2}{|c|}{ Total } & 145 & $100 \%$ \\
\hline Mean : 3.828 & Confidence Interval @ 95\%: [3.475 - 4.180] & Standard Deviation: $\mathbf{2 . 1 6 8}$ & Standard Error: 0.180 \\
\hline
\end{tabular}

\section{Interpretation:}

Most of the employees suffer from headache as per the above graph, followed by Anxiety and Neck ache and stomach disorders. These are a combination of both physical as well mental stress and effect on health. Employees face them as a result of stress.

\section{Q3. These factors make the employees feel that they are overloaded with work:}

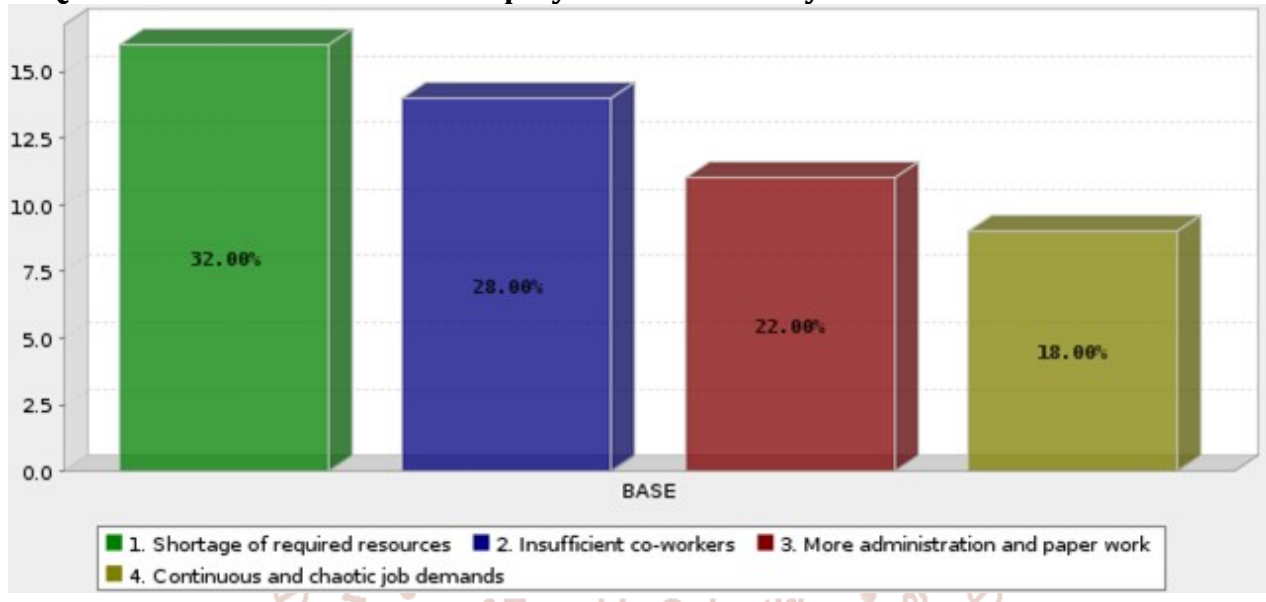

\begin{tabular}{|c|c|c|c|}
\hline & Answer & Count & Percent \\
\hline 1. & Shortage of required resources velopnent & 16 & $32.00 \%$ \\
\hline 2. & Insufficient co-workers & 14 & $28.00 \%$ \\
\hline 3. & More administration and paper work & 11 & $22.00 \%$ \\
\hline 4. & Continuous and chaotic job demands & 9 & $18.00 \%$ \\
\hline \multicolumn{2}{|r|}{ Total } & 50 & $100 \%$ \\
\hline Mean : 2.260 & Confidence Interval @ 95\% : [1.954 - 2.566] & Standard Deviation : 1.103 & Standard Error : 0.156 \\
\hline
\end{tabular}

Interpretation: employees are overloaded with work because of inadequate required resources and insufficient co-workers. Due to inadequate resources, the existing employees are burdened with more work and forced to complete them within a short period making them more stressed.

Q4: This is how employees feel that they have lack of control over any factors:

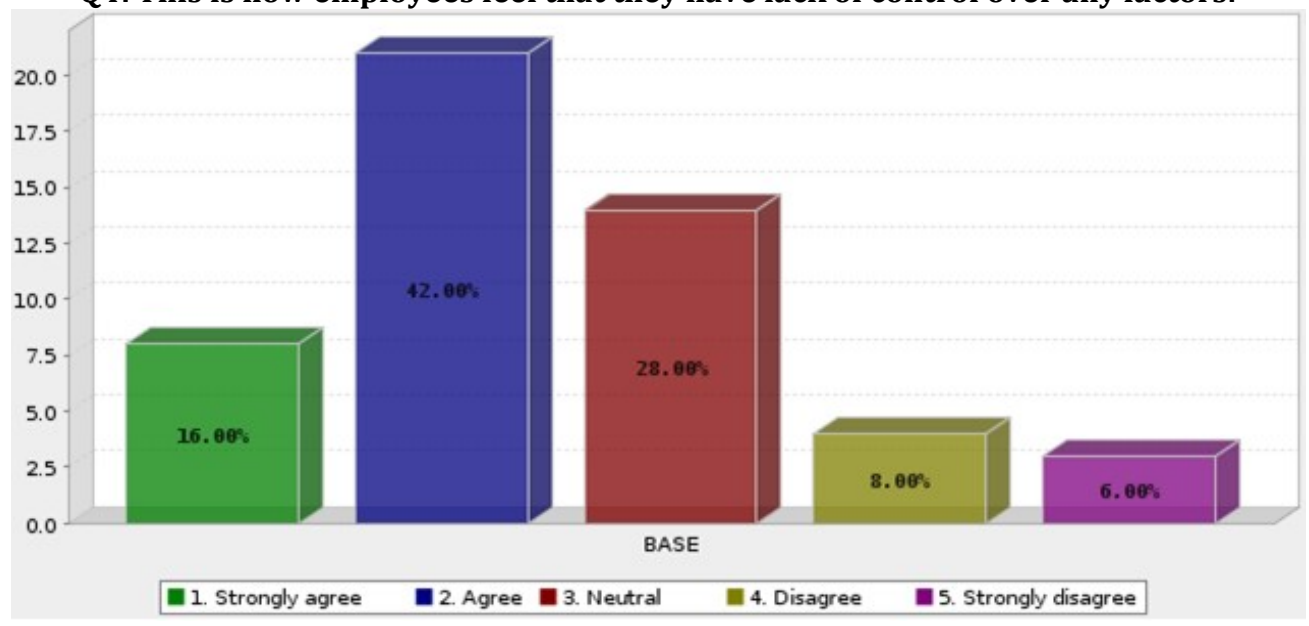


International Journal of Trend in Scientific Research and Development (IJTSRD) @ www.ijtsrd.com eISSN: 2456-6470

\begin{tabular}{|c|c|c|c|}
\hline & Answer & Count & Percent \\
\hline 1. & Strongly agree & 8 & $16.00 \%$ \\
\hline 2. & Agree & 21 & $42.00 \%$ \\
\hline 3. & Neutral & 14 & $28.00 \%$ \\
\hline 4. & Disagree & 4 & $8.00 \%$ \\
\hline 5. & Strongly disagree & 3 & $6.00 \%$ \\
\hline \multicolumn{2}{|c|}{ Total } & 50 & $100 \%$ \\
\hline Mean : 2.460 & Confidence Interval @ 95\% : [2.168 - 2.752] & Standard Deviation : 1.054 & Standard Error : 0.149 \\
\hline
\end{tabular}

Interpretation: The highest percentages of employees agree that they have lack of control over the factors that affect their stress level.

Q5 Employees feel that deadlines which are regularly too tight are a hindrance to completion of work

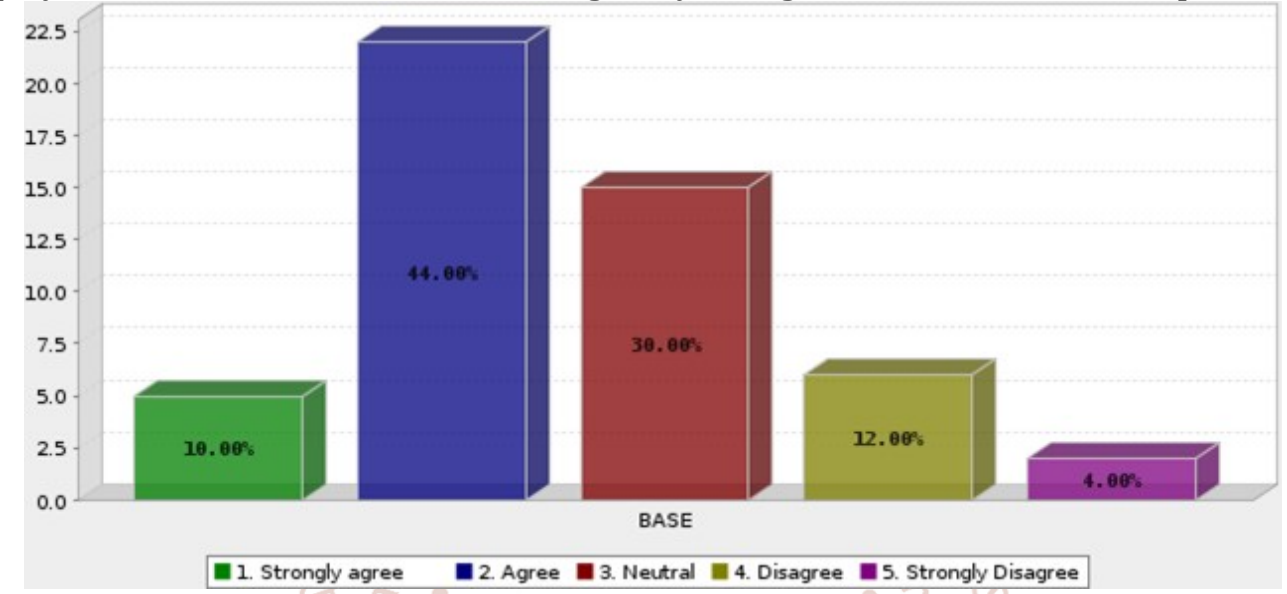

\begin{tabular}{|c|c|c|c|}
\hline & Answer & Count & Percent \\
\hline 1. & Strongly agree & 5 & $10.00 \%$ \\
\hline 2. & Agree & 22 & $44.00 \%$ \\
\hline 3. & Neutral & 15 & $30.00 \%$ \\
\hline 4. & Disagree & 6 & $12.00 \%$ \\
\hline 5. & Strongly Disagree & 2 & $4.00 \%$ \\
\hline \multicolumn{2}{|c|}{ Total } & 50 & $100 \%$ \\
\hline Mean : 2.560 & Confidence Interval @ 95\%: [2.291 - 2.829] & Standard Deviation: $\mathbf{0 . 9 7 2}$ & Standard Error : 0.137 \\
\hline
\end{tabular}

Interpretation: nearly $44 \%$ of the employees feel that regular deadlines to their work is making them more stressed. When the deadlines are too tight, employees are forced to sit overtime and complete the work in stipulated deadline, causing more stress to them. This directly affects their physical and mental wellbeing.

Q6: Employees feel that they seldom receive adequate acknowledgment or appreciation even though their work is really good, which causes more stress in their work

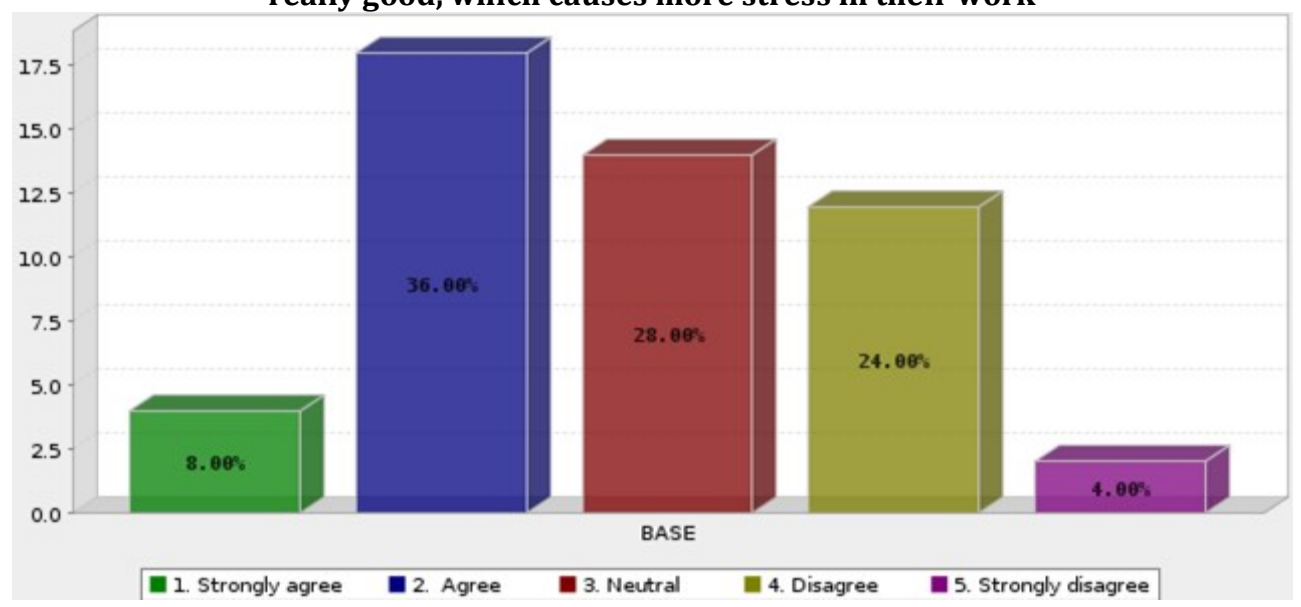


International Journal of Trend in Scientific Research and Development (IJTSRD) @ www.ijtsrd.com eISSN: 2456-6470

\begin{tabular}{|c|c|c|c|}
\hline & Answer & Count & Percent \\
\hline 1. & Strongly agree & 4 & $8.00 \%$ \\
\hline 2. & Agree & 18 & $36.00 \%$ \\
\hline 3. & Neutral & 14 & $28.00 \%$ \\
\hline 4. & Disagree & 12 & $24.00 \%$ \\
\hline 5. & Strongly disagree & 2 & $4.00 \%$ \\
\hline \multicolumn{2}{|c|}{ Total } & 50 & $100 \%$ \\
\hline Mean : 2.800 & Confidence Interval @ 95\% : [2.514 - 3.086] & Standard Deviation : 1.030 & Standard Error : 0.146 \\
\hline
\end{tabular}

Interpretation: Employees feel that they seldom receive acknowledgment in their work though they work hard and achieve all success in their work. They feel that their work isn't appreciated though they had put all their efforts in completing it.

Q7: Employees experience mood swings, difficulty in making decisions, their concentration and memory is impaired due to stress level at their work:

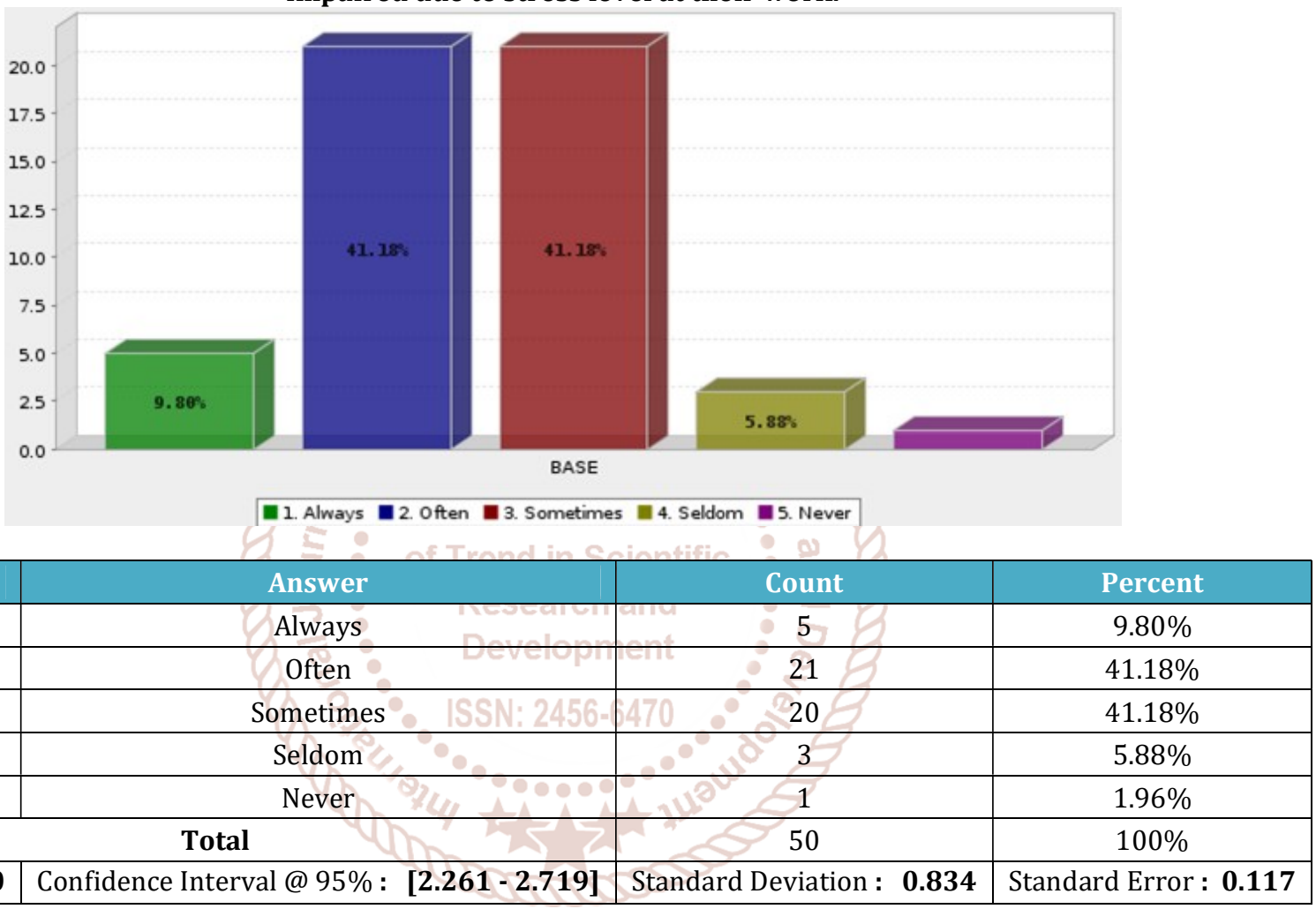

Interpretation: Employees have given their mixed views on this particular aspect. When we observe the graph as well the table, we can make out that $40 \%$ of people have said that they are Sometimes affected by these factors whereas the other $40 \%$ have said that they often face these difficulties like mood swings and concentration problem. These health problems arise predominantly due to the stress levels at workplace.

Q8: The graph depicts that employees feel that training related to the job would make them more efficient at work place, however they aren't getting enough training to make them more efficient and skilful:

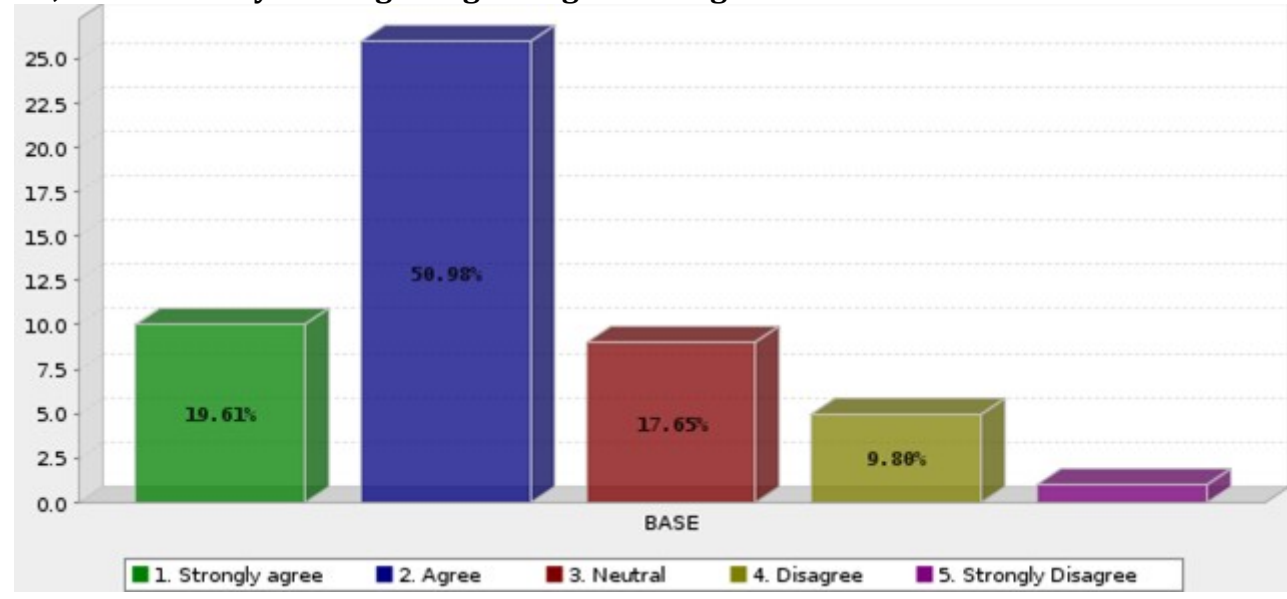


International Journal of Trend in Scientific Research and Development (IJTSRD) @ www.ijtsrd.com eISSN: 2456-6470

\begin{tabular}{|c|c|c|c|}
\hline & Answer & Count & Percent \\
\hline 1. & Strongly agree & 10 & $19.61 \%$ \\
\hline 2. & Agree & 26 & $50.98 \%$ \\
\hline 3. & Neutral & 9 & $17.65 \%$ \\
\hline 4. & Disagree & 5 & $9.80 \%$ \\
\hline 5. & Strongly Disagree & 1 & $1.96 \%$ \\
\hline \multicolumn{2}{|c|}{ Total } & 51 & $100 \%$ \\
\hline Mean: 2.235 & Confidence Interval @ 95\% : [1.974 - 2.496] & Standard Deviation : 0.951 & Standard Error : 0.133 \\
\hline
\end{tabular}

Interpretation: the graph as well the table portrays that employees agree that they need more effective training to be skilful and expert in their job. They feel that the training what they are getting at present is insufficient for the job requirements.

Q9: The graph indicates that employees feel Meditation, exercise, and talking to a friend serves as problemfocused coping strategies

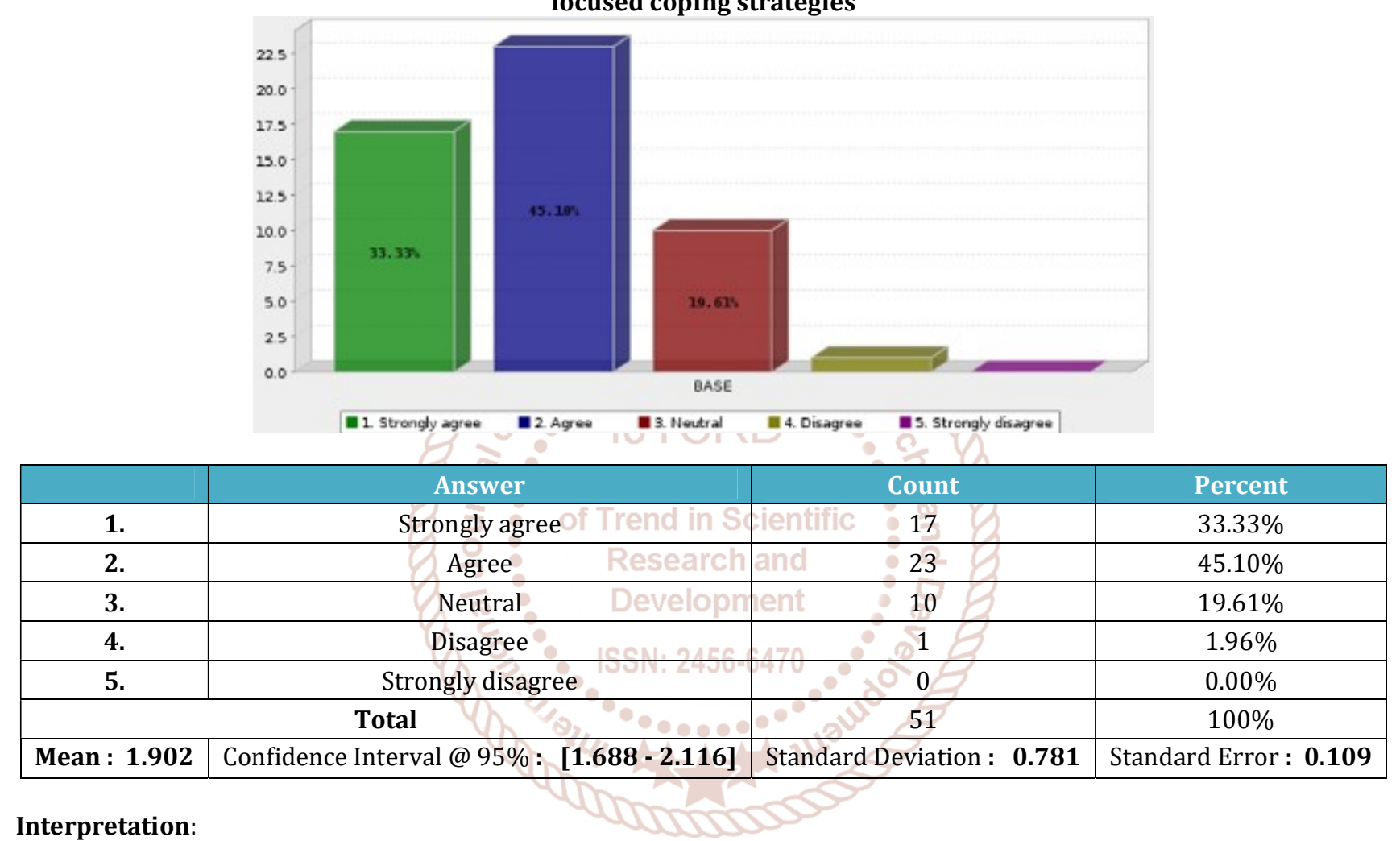

Employees have strongly agreed that spending quality time with their family and friends, indulging in meditation helps them to cope up with stress. They need a break with their friends and family during stressful times to relax and refresh themselves.

\section{Overall interpretation:}

Stress is an ever-growing phenomenon in the current day organization. Employees face more problems physically and psychologically gradually at their workplace. There are various known factors for stress like Overload of work, lack of supervision or too much of supervision, superiors at the work place, employees have given mixed responses to the questionnaire, but ultimately one can make out that Stress definitely rules employees mind and health in the current era.

\section{Suggestion and conclusion}

Workplace stress is very costly and impacts the business heavily. An employer can never take workplace stress casually because it directly influences the business revenue and the performance of their employees. The work stress is the common problem faced by employees worldwide and they must be kept happy in an organization since they are the assets of an Organization.

\section{Suggestions for Employers:}

$>$ Employers must design the work for employees in a way that they can give them enough space for their personal life. They can keep the workload appropriate for employee's as per their capabilities and potentialities and available resources.

$>$ Permitting the employees to work from home when they have a personal emergency instead of compelling or pressurizing them to come to organization and work.

$>$ Employers can arrange fun activities, it would be difficult to take their time off during the peak season or busy season of work, but employers can definitely allow employees to have fun for some 10-minute fun activities which would refresh their minds. They can make few power yoga sessions for a period of 15 minutes in the least.

$>$ Many companies are nowadays trying to cater to employee's stress. Few companies like Apple conducts Yoga session everyday for a minimum of 15 minutes to 30 minutes. 


\section{Suggestions for Employees:}

$>$ Employees can indulge themselves in performing simple exercises, which would help them to relax. They would feel strongest when exercised regularly.

$>$ Spending quality time with their friends and family would help them to refresh their mind and thoughts.

$>$ Deep breathing exercises can help activate parasympathetic nervous system, which controls the relaxation response. This helps in slowing heart rate, allowing employees to feel more peaceful.

$>$ They need to have food on proper time and refresh themselves with proper water supplements to keep themselves hydrated and energetic for managing work.

$>$ One can listen to soothing music and relax and relieve themselves from stressful thoughts.

\section{References:}

\section{Books:}

[1] Mohla Charu, "Effect of Occupational Stress on QWL: Amongst the Associates of all Industry, Vol. 6 (5 May 2013), Advances in Management." Pp 44-48

[2] David, M. (1998), "Motivational and stress management", Harvard Business School Publishing, Boston, Massachusetts, USA, Pp 167-177

[3] Stephen P. Robbins, "Organizational Behaviour", Prentice Hall, U.K.1999, Pp 20-22

[4] Gray P. "Mental Health in the Workplace: Tackling the Effects of Stress", Mental Health Foundation Publishers, London, 2000, Pp 54-58
[5] Aswathappa. K, "Organizational Behaviour", Himalaya Publishing House, 2016, Pp 20-22, 45-49, 112-115

[6] Cooper. C. L. and Marshall. J, "Understanding Executive Stress”, The McMillan Press Ltd, 1978, Pp 12-15

[7] Kothari C. R 'Research Methodology - methods and techniques", New Age International Publishers 2004, Pp 27-33, Pp 44- 45.

[8] Pestonjee "Stress and coping: the Indian experience" 2nd edition, New Delhi, Sage Publications 2004, Pp 4448

[9] Paul Hersey, Kenneth H. Blan chard, Dewey E. Johnson - "Organizational Behaviour", Prentice Hall of India Pvt. Ltd Publishers, 1998, Pp 23-30

[10] Lazarus, R.S, "Psychological Stress and Coping Process", McGraw Hill, New York 1966, Pp 18-19

\section{WEBLIOGRAPHY}

[1] Michie S "Causes and Management of Stress at retrieved on $01 / 28 / 2019$ on the website: http://oem.bmj.com/content/59/1/67.long

[2] WHO "Work organization and stress protecting workers' health", retrieved on $01 / 02 / 2019$ via the Website:

http://www.who.int/occupational_health/publications /pwh3rev.pdf 